\title{
LASER REMELTING OF Ni-Cr-Re PLASMA SPRAYING COATING
}

\author{
${ }^{1}$ Marek Stanisław WĘGLOWSKI, ${ }^{2}$ Jerzy DWORAK, ${ }^{3}$ Stanisław DYMEK, ${ }^{4}$ Izabela KALEMBA-REC, \\ ${ }^{5}$ Adriana WRONA, ${ }^{6}$ Katarzyna KUSTRA, ${ }^{7}$ Marcin LIS \\ ${ }^{1}$ Łukasiewicz - Institute of Welding, Gliwice, Poland, EU, marek.weglowski@is.gliwice.pl \\ Łukasiewicz - Institute of Welding, Gliwice, Poland, EU, jerzy.dworak@is.gliwice.pl \\ ${ }^{3} \mathrm{AGH}$, Faculty of Metals Engineering and Industrial Computer Science, Krakow, Poland, EU, \\ gmdymek@cyfronet.pl \\ ${ }^{4} \mathrm{AGH}$, Faculty of Metals Engineering and Industrial Computer Science, Krakow, Poland, EU, \\ kalemba@agh.edu.pl \\ ${ }^{5}$ Łukasiewicz - Institute of Non-Ferrous Metals, Gliwice, Poland, EU, adrianaw@imn.gliwice.pl \\ 6Łukasiewicz - Institute of Non-Ferrous Metals, Gliwice, Poland, EU, katarzyna.kustra@imn.gliwice.pl \\ 7Łukasiewicz - Institute of Non-Ferrous Metals, Gliwice, Poland, EU, marcin.lis@imn.gliwice.pl
}

https://doi.org/10.37904/metal.2020.3562

\begin{abstract}
The plasma spray technology allows spraying a wide variety of materials. Atmospheric plasma spraying (APS) consists in injecting a powder feedstock material in a plasma jet to melt and accelerate the injected particles and spray them onto a substrate. The coating growth is thus realized by the impingement and spreading of sprayed particles. This mechanism of coating formation induces the presence of pores and micro-cracks. In order to eliminate those drawbacks, laser remleting may be used to improve the properties and performances of plasma sprayed coatings. In the present paper, the Ni20\% $+20 \%$ Re coating fabricated by plasma spraying on stainless steel substrate were remelted by $\mathrm{CO}_{2}$ laser, and the effect of laser remelting on microstructure and hardness of plasma sprayed $\mathrm{Ni} 20 \% \mathrm{Cr}+20 \%$ Re coating were studied. The microstructure of plasma sprayed and laser remelted coatings were analyzed using scanning election microscopy (SEM) and energy disperse spectroscopy (EDS). The micro-hardness of coating was measured using micro-hardness tester. The results show that the laser remelted coating becomes much denser moreover, the chemical composition of the coatings becomes homogeneous
\end{abstract}

Keywords: Coatings, rhenium, thermal spraying, laser remelting, microstructure

\section{INTRODUCTION}

Rhenium is a refractory metal that has gained significant recognition as a high performance engineering material because it exhibits an outstanding combination of properties. Compared to the other refractory metals, Re has superior tensile strength and creep rupture strength over a wide temperature range (up to approximately $2000^{\circ} \mathrm{C}$ ). For example, between room temperature and $1200^{\circ} \mathrm{C}$, its strength is approximately double that of tungsten. In addition, the rupture strength of rhenium is greater than that of tungsten at temperatures approaching $2800^{\circ} \mathrm{C}$. At $2500^{\circ} \mathrm{C}$ its strength is comparable to the strength of carbon composites. Unlike other refractory metals $(\mathrm{W}, \mathrm{Mo}, \mathrm{Ta})$ it exhibits good ductility at room temperature. These properties makes rhenium an attractive candidate for numerous applications, especially in high-temperature structural and energy systems applications. Currently, additions of rhenium are commonly used in $\mathrm{Ni}$ - or Co-based superalloys for the purpose of improving the creep strength [1], reinforced composite [2] or manufacturing of coatings $[3,4]$. On the other hand, plasma spraying process is able to produce coatings with any chemical composition that are necessary for different industrial applications, spray on complex shapes as well as on elements with 
small thickness. The plasma spraying also allows for produce layers of a precisely defined thickness, contrary to the flame spraying process or weld cladding. The plasma spraying method is increasingly used for the production of coating on elements used in the aerospace and military industries. The main difficulty, however, is the fact that the spraying process does not allow for a uniform and compact coating within its entire volume. The plasma sprayed layers are usually characterized by porosity. In order to reduce it, the processes of laser beam remelting [5-10] or electron beam [11-13] can be used.

The paper presents the laser remelting processes of thermal spraying coatings in relation to microstructure and mechanical properties. The $\mathrm{Ni} 20 \% \mathrm{Cr}+20 \%$ Re alloys will be used in the investigation. The importance of this research is to create a scientific basis for adapting the plasma spraying method followed by remelting by high energy laser beam to produce coatings with novel alloys containing rhenium that can not be produced by conventional technologies.

\section{EXPERIMENTAL PROCEDURE}

$\mathrm{Ni} 20 \% \mathrm{Cr}+20 \% \mathrm{Re}$ coatings were prepared in three steps. Firstly, the plasma sprayed materials in the form of powder were produced at the Łukasiewicz - Institute of Non-Ferrous Metals from commercial NiCr powders by the modification of them with rhenium (Figure 1). The technique of powder modification with rhenium has been already elaborated at the Łukasiewicz - Institute of Non-Ferrous Metals. The proces is based on an application of thermo-chemical treatment for producing metallic rhenium from a raw material in the form of ammonium perrhenate directly on the surface of modified powders.

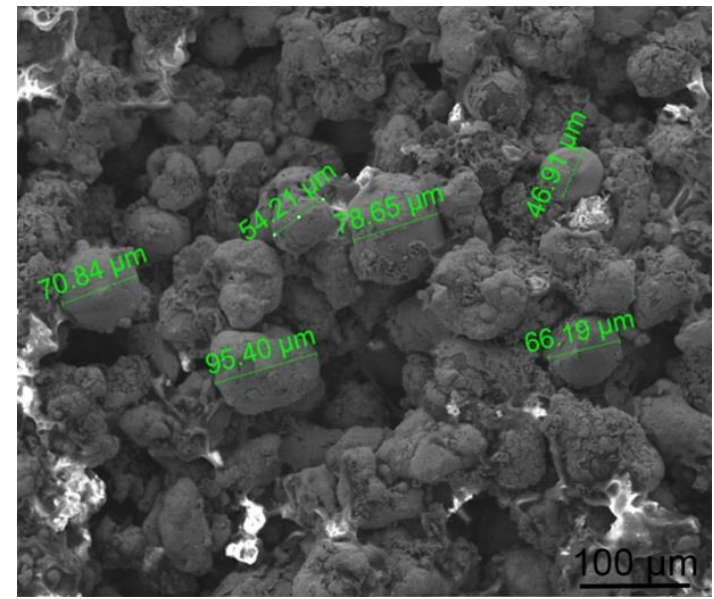

a)

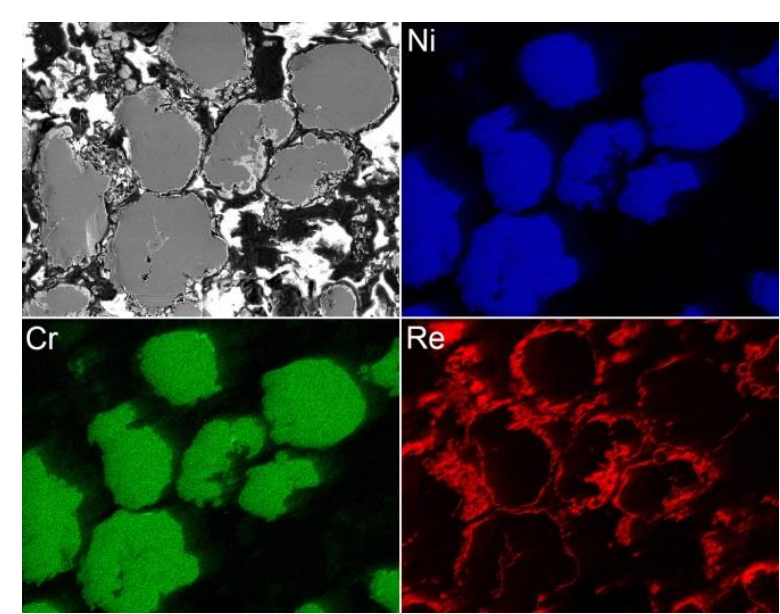

b)

Figure $1 \mathrm{Ni20} \% \mathrm{Cr}+20 \%$ Re powder for plasma spraying, a) general view, b) EDS analysis $-\mathrm{Ni}$ (blue), $\mathrm{Cr}$ (green), Re (red)

Secondly, manufactured alloy powders were sprayed on a ferritic stainless-steel (316Ti) substrate by an atmospheric plasma-spraying facility (AP-50 Plasma Spray System). The plasma spraying parameters: current $530 \mathrm{~A}$, arc voltage $690 \mathrm{~V}$, shielding gas flow rate $(\mathrm{Ar}) 54 \mathrm{l} / \mathrm{min}$, plasma gas flow rate $\left(\mathrm{H}_{2}\right) 9 \mathrm{l} / \mathrm{mi}$, transport gas flow rate (Ar): $5 \mathrm{l} / \mathrm{min}$, spray distance $140 \mathrm{~mm}$, travelling speed $0.4 \mathrm{~m} / \mathrm{s}$. Before plasma spraying the surface of the substrate was decreasing and oxide layers was removing. Abrasive blasting using corundum abrasive F36 (500 -600 $\mu \mathrm{m}$ grain size) and F40 (425-500 $\mu \mathrm{m}$ grain size) were applied. After plasma spraying, a coating $\sim 380 \mu \mathrm{m}$ in thickness was achieved. The average roughness of the APS surface was $19.42 \mu \mathrm{m}$. Finely, laser remelting was carried out on the coating using a laser $\mathrm{CO}_{2}$ generator (Trumpf Lasercell 1005). The travelling speed was $0.5 \mathrm{~m} / \mathrm{min}$ at a fixed laser head to work distance $(100 \mathrm{~mm})$, and laser power was applied: $3.5 \mathrm{~kW}$. High-purity argon gas (ISO 14175-I1-Ar) at flow rate $12 \mathrm{l} / \mathrm{min}$ was used to prevent oxidation during laser processing. The general view of sprayed surface and after laser remelting in (Figure 2) were presented. The 
resultant plasma sprayed and laser remelting coated samples (cross-section) were cut, polished and etched chemically $\left(\mathrm{NH}_{4} \mathrm{~F}+\mathrm{HNO}_{3}\right)$. The microstructures of the etched samples were investigated by scanning electron microscopy (SEM; FEI Nova Nano SEM 450) with energy dispersive spectroscopy (EDS). The microhardness of samples was measured by a TUKON 2500 digital microhardness tester with a load of $300 \mathrm{gr}$ for $10 \mathrm{~s}$. Microhardness measurements were performed on the substrate, bond layer and coating.

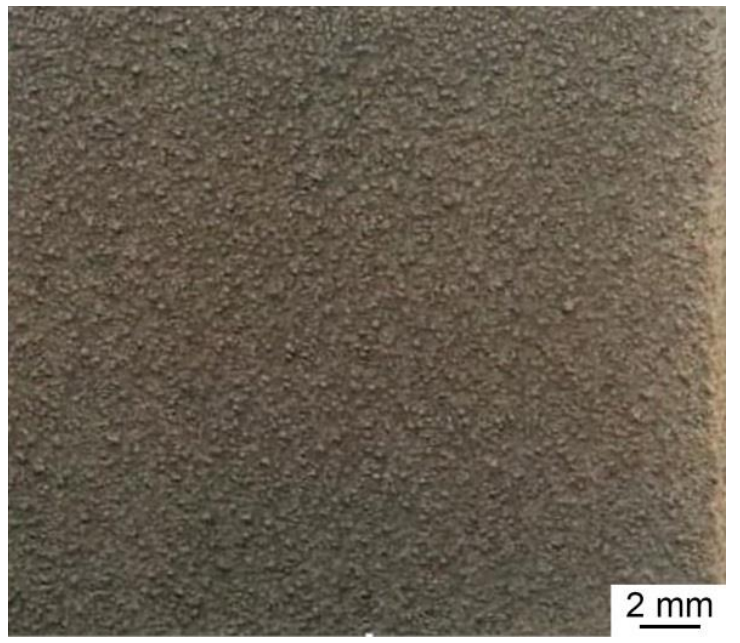

a)

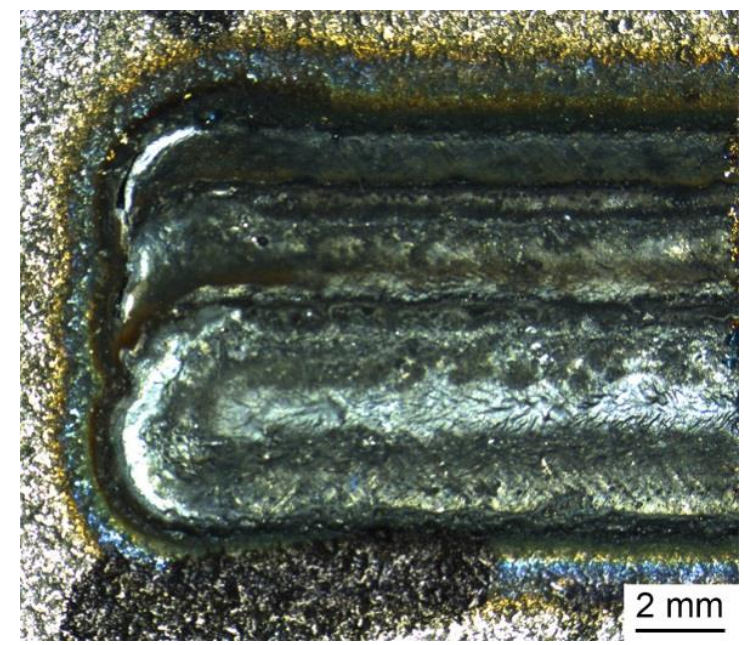

b)

Figure 2 General view of sprayed surface, a) after spraying, b) after laser remelting

\section{RESULTS AND DISCUSSION}

The cross-section SEM images of plasma-sprayed and laser remelted $\mathrm{Ni20} \% \mathrm{Cr}+20 \% \mathrm{Re}$ coatings are shown in (Figure 3). From the top to the down, there are the bond layer and ceramic coating in turn. The plasma sprayed coating has a typical plasma sprayed lamellar-like structure and contains a lot of pores and cracks (Figure 3a). Laser remelting can effectively reduce the pores and microcracks of the plasma sprayed coating, and the coating became much denser. In addition, the lamellar defects of the plasma sprayed coating were erased, and fine equiaxed grains with homogenous distribution were obtained (Figure $\mathbf{3 b}$ ). So the compactness of the plasma sprayed coating was improved significantly using laser remelting.

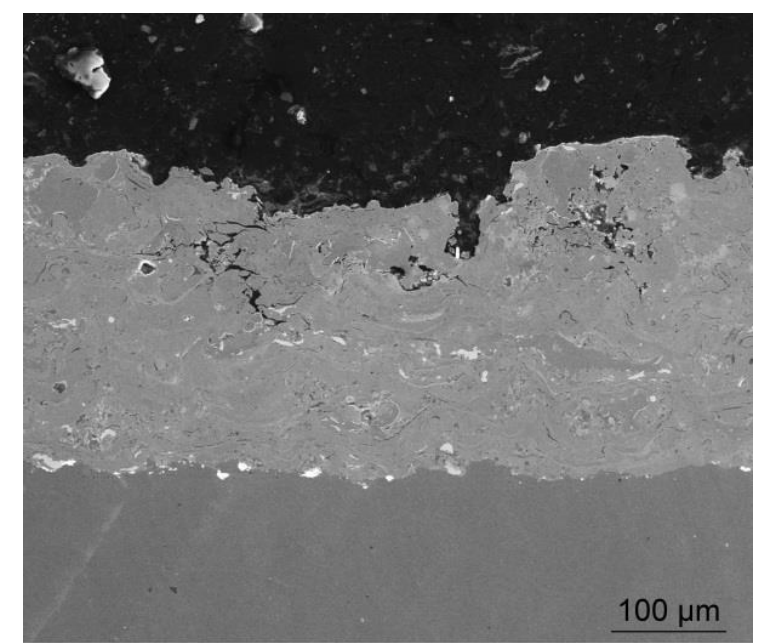

a)

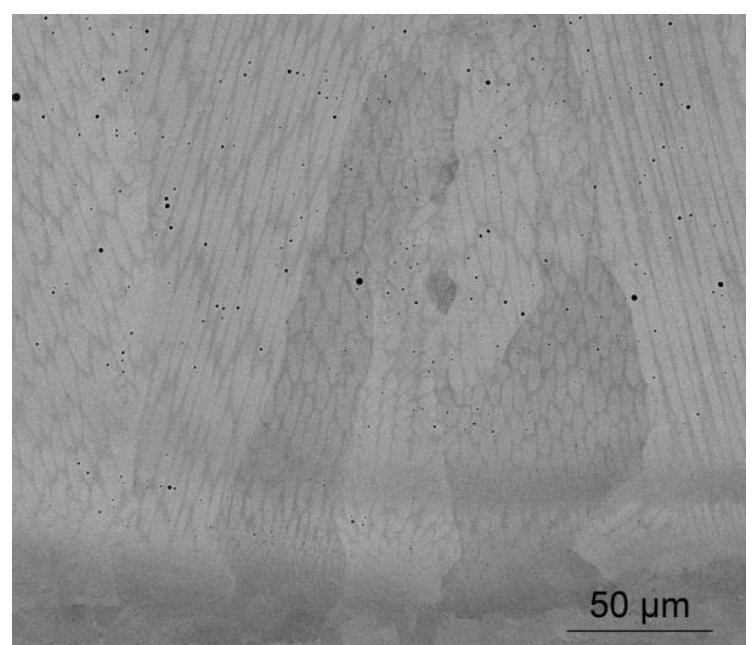

b)

Figure 3 The cross-section SEM images of coatings: (a) plasma-sprayed; (b) laser remelted. 
The micro-area chemical composition of the plasma-sprayed coating are analyzed. The high-magnification SEM of cross-section of coating and EDS of different micro-areas are shown in (Figure 4). The analysis of the chemical composition of the $\mathrm{Ni}-\mathrm{Cr}-\mathrm{Re}$ coating, revealed that the ratio of nickel and chromium in different areas is not the same. It was found that the distribution of elements is uneven. There are areas consisting mainly of nickel and chromium (darkest), nickel and chromium with approx. $20 \%$ rhenium addition (lighter) and only rhenium (white).

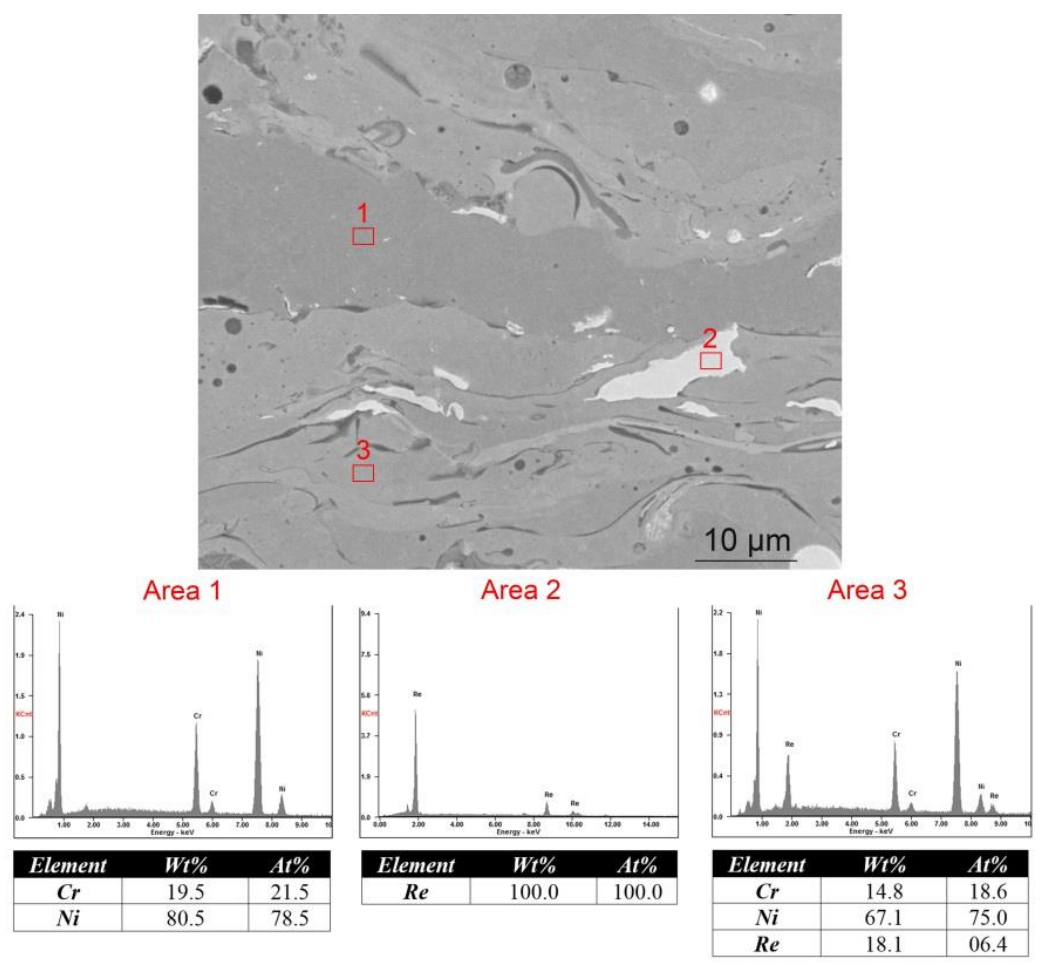

Figure 4 The corresponding EDS result of different micro-areas of the plasma-sprayed coating

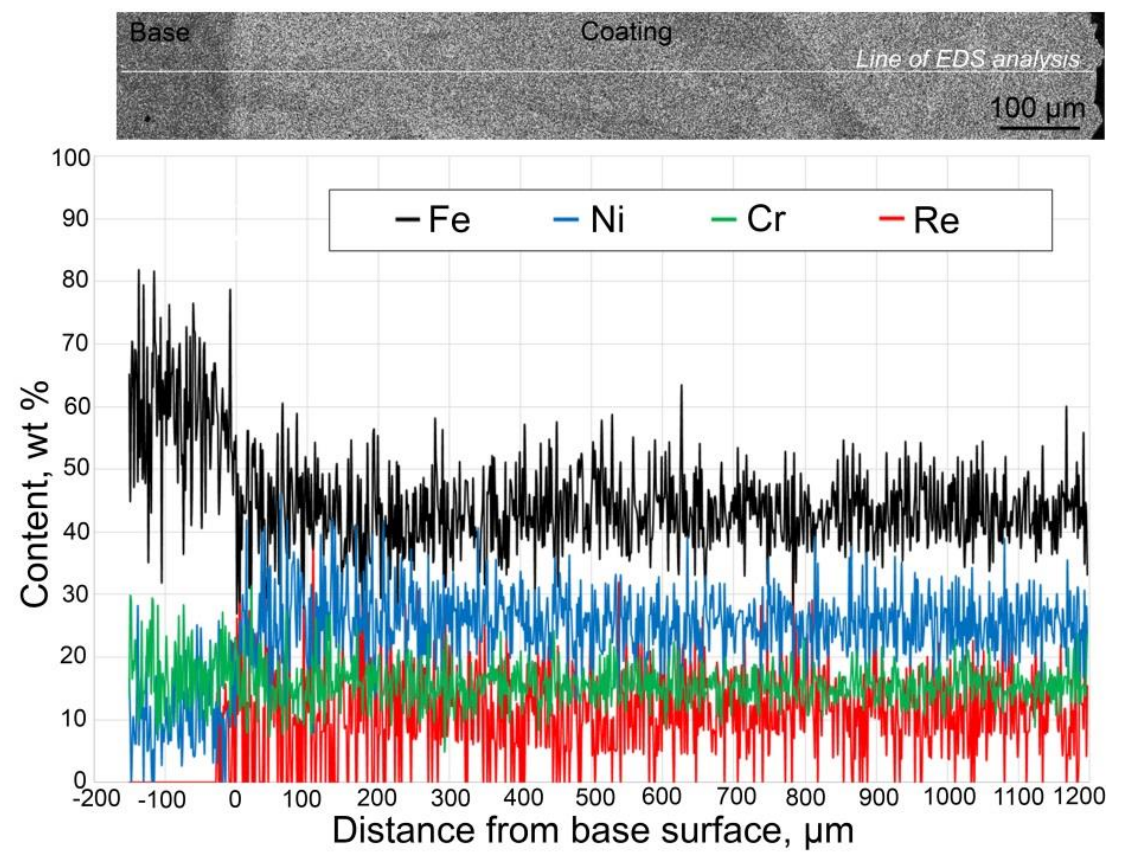

Figure 5 The line scanning pattern of the plasma-sprayed coating after laser remelting 
Figure 5 presents the EDS line scan images of plasma-sprayed coatings after laser remelting. The content of $\mathrm{Cr}$ (blue line) is in the range up $25 \%$ in the area of surface and decrease to $14.9 \%$ (average value). The content of $\mathrm{Fe}$ (purple) in the surface region is higher (up 70\%) while lower in the remelted plasma-sprayed coatings region (about 47.9\%). Conversely, the content of $\mathrm{Ni}$ (yellow) in the surface region is much lower (about 10\%) while higher in the remelted plasma-sprayed coatings region (about $25.9 \%$ ). Finally, the content of Re in the plasma-sprayed coatings after laser remelting amounts about $10 \%$ (green line). After laser melting, the lamellar structure disappears and the laser-remelted coating becomes homogeneous in composition (Figure 5).

The hardness distribution of the plasma-sprayed coating after laser remelting in (Figure 6) was presented. It was revealed that the hardness of $\mathrm{Ni}-\mathrm{Cr}$ - $\mathrm{Re}$ coating is higher than $\mathrm{Ni}-\mathrm{Cr}$ after laser processing. Moreover, the hardness in separated points after remelting process becomes lower to compare to coating without remelting. This is caused, probably by high content of $\mathrm{Fe}(46.9 \%)$ in the processing plasma-sprayed coating to compare to plasma-sprayed direct after spraying with $\mathrm{Ni} 20 \% \mathrm{Cr}+20 \% \mathrm{Re}$.

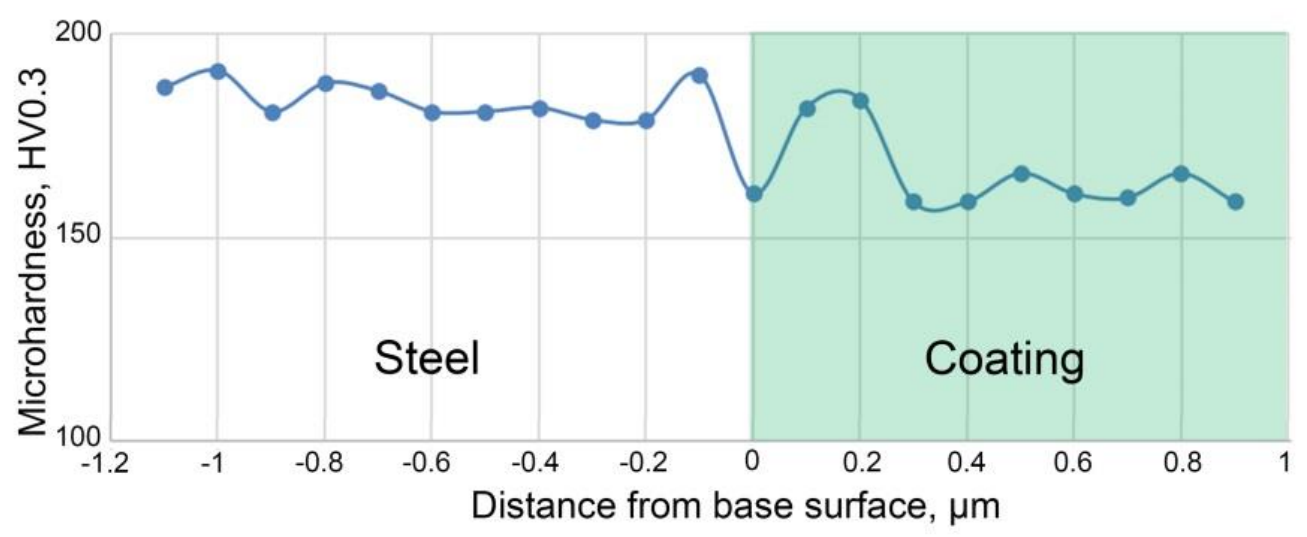

Figure 6 The line scanning pattern of the plasma-sprayed coating after remelting

\section{CONCLUSION}

In this work, $\mathrm{Ni} 20 \% \mathrm{Cr}+20 \% \mathrm{Re}$ coating fabricated by plasma spraying was remelted by $\mathrm{CO}_{2}$ laser, and the effect of laser remelting on microstructure and harndess of coating was studied.

- the plasma sprayed coating shows a lamellar-like structure and has a lot of pores. The microcracks were also detected. Laser remelting can reduce the pores and microcracks and eliminate the lamellar defect. The microstructure of the coating becomes homogenous and compact,

- $\quad$ the scanning speeds of the laser beam in the process of remelting of plasma sprayed layers have a significant impact on quality. More favorable layer properties ensure at less scanning speeds,

- $\quad$ un-remelted coating is characterized by higher hardness in relation to those subjected to the laser treatment process, moreover after laser remelting the chemical composition of the coatings becomes homogeneous.

\section{ACKNOWLEDGEMENTS}

This work has been performed with funding from National Science Centre in Poland within the frame of the research grant UMO-2018/29/B/ST8/01206 entitled: "Multi scale analysis of microstructural changes in wear resistant coatings produced by plasma spraying followed by remelting with an application of concentrated energy sources in view of the improvement of their mechanical properties". 


\section{REFERENCES}

[1] NAOR, A., ELIAZ, N., et al. Properties and Applications of Rhenium and its Alloys, The AMMTIAC Quarterly. 2010, vol. 5, no. 4, pp. 11-15.

[2] WĘGLOWSKI, M.ST., WRONA, A., RICHERT, M., NEJMAN, I. Microstructural evaluation of Re particle reinforced composite on aluminium surface by friction stir processing. Építőanyag - Journal of Silicate Based and Composite Materials, 2018, vol. 70, no. 6, pp. 181-185.

[3] MOSKAL, G., MIGAS. D., et al., Characterization of the Gradient (Mo, Re)Si-2/Mo-Re Coatings Deposited in the Hybrid Process. Journal of Thermal Spray Technology, 2019, vol. 28, no. 7, pp. 1532-1553.

[4] TREFON-RADZIEJEWSKA, D. JUSZCZYK, J., et. al. Thermophysical properties of refractory W-50.4\%Re and Mo-39.5\%Re thin alloy layers deposited on silicon and silica substrates. 2020, vol. 87, no. 2, paper 105147.

[5] AFZAL, M., AJMAL, M., et . al. Surface modification of air plasma spraying WC-12\%Co cermet coating by laser melting technique. Optics \& Laser Technology, 2014, vol. 56, pp. 202-206.

[6] HAZRA, S., DAS, J., et. al. Synthesis of mullite-based coatings from alumina and zircon powder mixtures by plasma spraying and laser remelting. Materials Chemistry and Physics, 2015, vol. 154, pp. 22- 29.

[7] ZHU C., LI P., et. al. An investigation on the microstructure and oxidation behavior of laser remelted air plasma sprayed thermal barrier coatings. Surface \& Coatings Technology, 2012, vol. 206, pp. 3739-3746.

[8] DAS B., NATH, A.K., et. al. Online monitoring of laser remelting of plasma sprayed coatings to study the effect of cooling rate on residual stress and mechanical properties. Ceramics International, 2018, vol. 44, pp. 7524-7534.

[9] GHASEMI, R., SHOJA-RAZAVI, R., et al. The influence of laser treatment on hot corrosion behavior of plasmasprayed nanostructured yttria stabilized zirconia thermal barrier coatings. Journal of the European Ceramic Society, 2014, vol. 34, pp. 2013-2021.

[10] HENGST, P., ZENKER, R., et. al. Electorn beam profiling and electron beam remelt-bonding for improving the load - bearing capacity of thermal spray coatings. International Electron Beam Welding Conference, Aache, 2017.

[11] JUNG, A., BUCHWALDER, A., et. al. Surface engineering of spray-formed aluminium-silicon alloys by plasma nitriding and subsequent electron beam remelting. Surface and Coatings Technology, 2018, vol. 335, pp. 166172.

[12] WU, Y.Z., LIAO, W.B., et al. Effect of electron beam remelting treatments on the performances of plasma sprayed zirconia coatings. Journal of Alloys and Compounds, 2018, vol. 756, pp. 33-39.

[13] BUCHWALDER, A., ZENKER, R. Pre- and post-surface treatments using electron beam technology for loadrelated application of thermochemical and PVD hard coatings on soft substrate materials. Surface \& Coatings Technology, 2019, vol. 375, pp. 920-932. 